\title{
Surgeon-Major Ronald Ross, IMS Nobel Laureate in Medicine (1902) for his work on malaria
}

\author{
2Lt N Martin \\ RAMC
}

HIS RHQ RAMC, Keogh Barracks, Ash Vale, Aldershot, Hants, GU12 5RQ.

\section{INDIAN FEVERS}

In this, $O$ Nature, yield I pray to me. I pace and pace, and think and think, and take. The fever'd hands, and note down all I see, That some dim distant light may haply break

The painful faces ask, can we not cure?

The answer, no, not yet; we seek the laws.

$O$ God, reveal thro' all this thing obscure,

The unseen, small, but million-murdering cause.

\section{Ronald Ross}

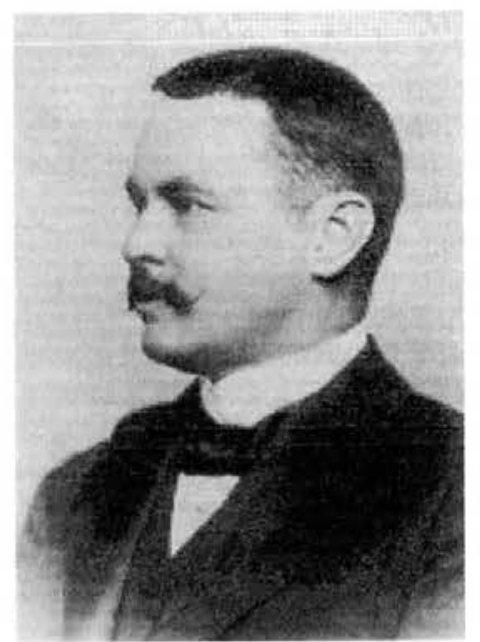

\section{Surgeon-Major Ronald \\ Ross, IMS}

Ronald Ross was born on Friday 13th May, 1857, at Almora in the Kumaön Hills, India, the son of Sir CCG Ross, a General in the English Army. At the age of 17, Ross professed an interest in art, or the army or navy, as a future career, but his father opposed these decisions, having set his heart on his son joining the medical profession, in particular, the Indian Medical Service (IMS).

He commenced his study of medicine at St. Bartholomew's Hospital in London in 1874. disliking much of the course, but finding that physiology, histology and microscope work engaged him more '... because they invoked problems of causation and the wonders of the body's mechanism ...' He passed his examinations in 1881, and entered the IMS, his commission as Surgeon taking him first to the Royal Victoria Hospital and School at Netley for the prescribed course of military medicine and surgery.

For the next five years he was put in medical charge of various infantry units, his apathy for medicine driving him towards mathematical studies, poetry, prose and music. In 1883, he was given the Acting Garrison Surgeoncy at Bangalore, a large garrison whose troops included both British and Indian cavalry, artillery and infantry. It was during this attachment that Ross first became interested in mosquitoes. He was repeatedly bitten until he discovered them breeding in a watertub just outside his window; he rid himself of the problem simply by emptying it of water. The adjutant, however, was scornful of this simple remedy, saying that ' ... it would be upsetting the order of nature ... as mosquitoes were created for some purpose, it was ... duty to bear with them ...'

In 1890, Ross was appointed the Staff Surgeoncy, and surrounded by enough sickness to keep him in a permanent state of anxiety. This turned out to be the turning point for Ross and his apathy of medicine, serving to encourage him to labour at his chosen profession, becoming especially interested in the multitude of fevers, especially the slighter ones, writing several papers on them in the process. At around this time, Alphonse Laveran's discovery (made in 1880) that malaria was caused by a blood parasite gradually began to filter into India. Ross was not convinced at first, and became equally sceptical about the other theories of the so-called malarial fevers being caused by aerial miasmas arising from marshes; if that were the case, most people in the vicinity of marshes would be infected.

As time went by, conditions available to his research on malaria deteriorated and his studies did not advance, throwing him back to his previous state of apathy. The responsibilities of his professional military work were also often trying because he and his colleagues did not know at the time the nature of most of the illnesses which they were obliged to deal with. He wrote the verses at the beginning of this article during this period.

Ross returned to England in 1894, determined to learn as much as he could about current research on malaria as the IMS libraries were incredibly out-of-date. He became convinced that Laveran's discovery was sound, and that the process of exflagellation that Laveran had reported was indeed a sign of a minute parasite which resided in or on the human erythrocyte. His studies put him in contact with Dr Patrick Manson and Ross discussed with him his recent work in China. The two men eventually came up with a viable theory whereby Manson proposed that malaria and mosquitoes were intimately linked together, much as he had recently found with the filarial parasite in China. Manson's hypothesis was not new; others had had the same idea, but mostly on very inadequate grounds. This working biological hypothesis originated from the fact that the crescentshaped bodies seen in freshly-drawn samples of malarial blood swell up and exflagellate when observed under a microscope. He believed that when a mosquito drew blood, these 'sexual' elements entered its stomach and took up residence in its tissues where they were able to develop further. We now know that his hypothesis went astray with the assumption that this unknown stage then entered the drinking water to promote the spread of malaria. Nevertheless, Ross was immensely impressed and became determined to test the hypothesis thoroughly upon his return to India.

Before leaving England in 1895, Ross won the Parkes' Memorial Gold Medal with a prize of seventy five guineas given by the Army Medical Service at Netley Hospital for an essay on malaria, the chief merit of which was its destructional analysis of the current textbook theories of aerial convection of the infection from marshes or the soil.

After the revolutionary discovery by Laveran, an all important question arose - How do these parasites manage to effect an entry into the blood of man and animals? Most observers, obsessed with the fact that the disease abounded near marshes, assumed that Laveran's parasites must be capable of living in a changed form in stagnant water. Following his conversations with Manson, Ross invented a small, portable microscope, useful for high powered analyses but capable of being slung around the shoulder like a pair of binoculars.

Once back in India, Ross began at once to collect mosquitoes and to devise methods of analysing them. His main aim was to study the Plasmodia, not in man, but in the mosquito, a thing 
which had never yet been attempted. Within a month, he had shown that the crescent-sphere-flagella phenomenon occurred in the mosquito's stomach in such a way as to suggest that the mosquito's stomach was the natural locus for the parasite.

In a letter to Dr Manson on 18th July 1895, Ross described one of his flagellate 'spores' attacking three leucocytes over the course of three hours, after which it appeared to die. One of his explanations was that it was '... probably mistaking them for some other cell ...'. Indeed, so obsessed was Ross with Manson's hypothesis that these were flagellated spores, that he was blind to the fact that these were the sexual elements of the malaria parasite. By 1896, these 'adventures of a flagellum' as he described them bothered him because they seemed to serve no purpose, on top of which, he constantly observed that no more than $60 \%$ of the crescent-spheres would release flagellae, while the remaining $40 \%$ or more continued to remain unchanged. He could think of no reason for this, trying for hours at a time to get the last few to release their hidden cargo, and yet the explanation was simple - those that released their contents were the male elements, the others the female targets. In early 1897, he observed two parasites ' ... lying close together, one emitting a number of struggling flagellae, and the other remaining a perfect sphere with one of the flagella moving slowly within it ...'. Ross believed this last flagellum was trying to leave the sphere; in fact, it was a lucky male gamete that had penetrated the female gamete and now prevented the others from entering. If Ross had observed this slide a few minutes previously, he would have seen the actual fertilisation, but instead, a few months later, an American malariologist, WG MacCallum, witnessed the act and proved that these were in fact gametes.

Much of Ross's early work was hampered by the fact that he was not an entomologist and knew nothing about the mosquitoes of India, nor how to identify them. He referred to the mosquitoes he worked with as 'brown-bodied' or 'brindled' mosquitoes; unfortunately, these were of the genus Aedes and Culex, neither of which are able to transmit malaria in humans. He theorised that each of the different species of mosquito contained many different parasites and that to solve the problem of malaria, he would have to identify the species of mosquito and which of the many parasites it carried was responsible; the only method of solution he could see for an equation with two unknowns was that of incessant trial and exclusion, an arduous task after already spending two years on malarial research.

After being posted to Secunderabad in 1897, he began to concentrate his attentions on the large, brown, 'dapple-winged' mosquito belonging to the genus Anopheles. Finally, he began to make progress. On 20th August 1897, his dissections of mosquitoes which had fed on malarial blood a few days previously revealed large clear cells within the normal architecture of the mosquito's gut. In each of these cells was a cluster of small granules, exactly like those of the Plasmodium crescent-shaped bodies, and which he had only found in the Anopheles mosquito. Noting down his findings, Ross slept after hours at the microscope in the heat of the Indian summer. When he awoke, he realised the magnitude of his finding; his clear cells were zygotes, female crescents which had been fertilised by the male gametes, released from the male crescents and referred to as the 'flagellated spores'. These clear cells still retained their original pigmentation and were actively growing in the gastric cells. With an extremely lucky observation, Ross had discovered both the unknown quantities simultaneously; the mosquito was Anopheles and the parasite lived within the gastric tissue, recognisable by its retained pigmentation.

On 24th September 1897, Surgeon-Major R Ross IMS, was ordered to proceed to Bombay for military duties. As he recounts in his memoirs, '... I saw the Promised Land, but was not allowed to enter it ...'. Ross tried hard to delay his move, furious with his military superiors who had failed to see the scope of his work. He was transferred on to Kherwara, where there was no malaria, and then on to Calcutta. He was unable to find any volunteers for his malarial research in the disease-ridden city, however, because a number of rumours had spread regarding the dangers of English doctors and their experiments. Desperate to continue his work, he began to use avian malaria as a model with which he hoped to extrapolate to human malaria.

Realising the significance of this sexual phase, Manson urged Ross to follow the development of these zygotes as they passed through the mosquito, although he believed that Ross would ultimately find that the parasites would release themselves into the environment. In June 1898, Ross began the final phase of his research. The zygotes had now been traced up until seven days of maturation, whereupon they burst, evidently ripe, yet with no visible products. After some scrutiny, he eventually identified what he called 'germinal rods' pouring out of the mature gastric cell, then traced them moving through into the coelom and thorax, concluding that they were trying to gain access to the mosquito's circulatory fluids. Finally, after further painstaking work with the microscope, sometimes spending over eighteen hours a day at his task, Ross wrote to Manson on 6th July 1898 to describe his germinal rods in the head of the mosquito, more specifically in a "... worm-like gland with an air tube down the middle ...', packed into the cells lining the air tubes. The gland proved to be extremely delicate and broke easily during the dissection, making it particularly difficult to isolate, but eventually he managed to get an intact dissection and proved that it was a salivary gland leading directly to the mosquito's proboscis. In the same letter, he concluded that ' ... Malaria is conveyed from a diseased person or bird to a healthy one by the proper species of mosquito, and is inoculated by its bite ...

Ross had finally succeeded in demonstrating the mosquito part of the Plasmodium's exceedingly complex life cycle. It was announced by Manson at the meeting of the new Tropical Diseases Section of the British Medical Association, held in Edinburgh between 26th-29th July 1898. Although he had used avian malaria to study the parasite, he was confident that the process was exactly the same in the human form of malaria. But, despite acknowledging his achievements with malaria, the Director General insisted that Ross move on to study the disease kala-azar, a disease that he knew and cared nothing about. The proof of the spread of human malaria by Anopheles mosquitoes came shortly afterwards, but this was eventually seen as a progression of the work carried out by Ross, and with support from much of the scientific community, Ross, and Ross alone, was awarded the Nobel Prize in Medicine in 1902.

Additional reading:

Ross, R. Memoirs (with a full account of the great malarial problem and its solution). John Murray (Press), 1923. 